\title{
Multi-Micronutrient Supplementation and Immunoglobulin Response in Well-Fed Firefighters
}

\section{()(1) $(\Theta$}

\author{
Authors \\ José Augusto Rodrigues Santos ${ }^{1}$, Ricardo J. Fernandes ${ }^{1,2}$, Rodrigo Zacca 1, 2, 3
}

\section{Affiliations}

1 Centre of Research, Education, Innovation and Intervention in Sport (CIFI2D), Faculty of Sport, University of Porto, Porto, Portugal

2 Porto Biomechanics Laboratory (LABIOMEP-UP), University of Porto, Porto, Portugal

3 Ministry of Education, CAPES Foundation, Brazilia, Brazil

Key words

exercise, immunoglobulin, nutrition, firefighters, training

received 26.03.2020

accepted after revision 22.10 .2020

published online 2020

\section{Bibliography}

Sports Medicine International Open 2021; 4: E1-E7

DOI 10.1055/a-1296-1486

ISSN 2367-1890

(c) 2020. The Author(s).

This is an open access article published by Thieme under the terms of the Creative Commons Attribution-NonDerivative-NonCommercial-License, permitting copying and reproduction so long as the original work is given appropriate credit. Contents may not be used for commecial purposes, or adapted, remixed, transformed or built upon. (https://creativecommons.org/ licenses/by-nc-nd/4.0/)

Georg Thieme Verlag KG, Rüdigerstraße 14,

70469 Stuttgart, Germany

\section{Correspondence}

Dr. Rodrigo Zacca

Centre of Research, Education, Innovation and Intervention in Sport (CIFI2D), Faculty of Sport, University of Porto, Porto

R. Dr. Plácido da Costa 91

4200-450 Porto

Portugal

Tel.: + 351225074763

rzacca@fade.up.pt

\section{ABSTRACT}

Intensive physical training programs can affect the immune system. This study aims to verify the multi-micronutrient supplementation effects on serum immunoglobulins levels prior to and after a five-week physical training program. Twenty-four male recruit firefighters were randomly allocated into supplemented (with Prisfar Ever-Fit Plus over 35 consecutive days) and placebo groups $(n=12$ each). Serum immunoglobulins $G$, $A$, and $M$ were assessed. Supplementation effect was detected for immunoglobulin $\mathrm{G}$ (eta-squared, $\eta^{2}: 0.09 ; p=0.035$; power: $0.56), A\left(\eta^{2}: 0.24 ; p=0.001\right.$; power: 0.95$)$, and $M\left(\eta^{2}: 0.09\right.$; $p=0.036$; power: 0.56 ). Although immunoglobulin $A$ was different between groups at baseline (mean difference: 42.58 ; $95 \% \mathrm{Cl}: 7.00$ to $78.16 \mathrm{mg} / \mathrm{dL} ; p=0.021 ; d=2.48)$, within-group (before vs. after five weeks) showed no differences for both supplemented and control groups. In addition, even if immunoglobulin $\mathrm{G}$ and $\mathrm{M}$ were similar at baseline, immunoglobulin $G$ decreased (mean diff.: 46.4; $95 \% \mathrm{Cl}: 6.7$ to $86.1 \mathrm{mg} / \mathrm{dL}$; $p=0.03 ; d=0.74$ ) and immunoglobulin $\mathrm{M}$ increased (mean diff.: $-10.7 ; 95 \% \mathrm{Cl}:-15.8$ to $-5.5 \mathrm{mg} / \mathrm{dL} ; p=0.001 ; d=-1.33$ ) in the control group. Although mean values remained within the reference values, changes observed for immunoglobulin $G$ and $\mathrm{M}$ may reflect some immune protection for firefighters engaged in recruit training. 


\section{Introduction}

Intensive physical training alters body immune/inflammatory responses [1], predisposing athletes to infections and injuries with a deleterious impact on training and performance [2]. The control of changes in the immune system is necessary to avoid pathological adaptations. Immunoglobulins protect against antigens (i.e. viruses and bacteria, or deleterious substances produced by the body itself) [2]. Five classes of immunoglobulins are formed by plasma cells: $\lg G$, IgM, IgA, IgD, and $\lg E$, all having different properties and functions [3]. Most serum immunoglobulins are lgG (75\%), followed by $\lg A(15 \%)$ and $\lg M(10 \%)[4,5]$, which are the main focus for this study. IgM is the first antibody to be expressed and produced (main functions: activating complement and agglutination, and has isohaemagglutination activity). $\mathrm{lgG}$ is the most abundant antibody in the blood and does the most in terms of protection (main functions: opsonization, agglutination, placental transfer, antibody-dependent cell-mediated cytotoxicity. and neutralization of toxins). IgA is the most abundant immunoglobulin in the mucosal system (main functions: agglutination and antiviral capacity). They are crucial components of humoral immunity, with pathogen neutralization and opsonisation functions occurring during primary and/or secondary antibody responses [2-6]. They also regulate cellular cytotoxic activity via sensitisation of natural killer cells, phagocytes, and mast cells, and promote inflammatory responses and clearance of immune complexes via activation of the complement system $[2,6]$.

The literature review on immunoglobulin responses makes it possible to distinguish between acute effects and chronic adaptations induced by different types of exercises $[2,7,8]$. There seems to be a well-established pattern: the more intense and prolonged the exercise, the more marked the acute response and the longer the recovery of baseline levels of the immune system [2]. Endurance training increases IgA and IgM basal levels [1]. Moderate exercise tends to stimulate $\mathrm{lgG}$ production. However, master athletes engaged in high-intensity and long-duration training, recreational athletes training at moderate intensity and duration, and sedentary individuals presented similar $\operatorname{lgG}$, IgA, and IgM serum concentrations [1]. It was also evidenced that low- to moderate-intensity exercises increase IgA basal levels $[9,10]$ and that IgG and IgM are maintained at a high level across a training period [9]. Conversely, high-intensity training promoted an IgG and IgM decrease whereas IgA remained stable [11], and a bout of 60 min downhill running (14 days after the first one) induced low $\mathrm{lgG}$ and IgE serum concentrations (chronic effect) [2]. In addition, it was observed that some acute alterations induced by intensive physical exercise are no longer visible after a few days of training [12]. Thus, even if systematic training seems to dampen the autoimmune inflammatory response, there is an evident discrepancy among studies, probably due to exercise mode and training specificity.

Micronutrient supplementation is widely used as a usual practice in disease and sport. In patients with diabetes, it improved celIular immunity without significant effects on $\lg A$, IgM, and IgG serum concentrations [13] and, in healthy elderly sedentary persons, a milk-based wolfberry formulation increased the serum IgG level [14]. Data are conflictual in sport-related studies, depending substantially on the type of supplement used. In fact, whereas supplementation with the flavonoid Quercetin did not damp the IgA salivary activity decrease after $160 \mathrm{~km}$ of running [15], melatonin ingestion increased serum IgA concentration 60 min after acute exercise [16] and probiotics consumption attenuated the salivary IgA decrease post intensive military training [17]. In addition, bovine colostrum supplementation prevented a post-exercise decrease in serum IgG levels in highly trained cyclists [18] and increased serum $\lg \mathrm{A}$ in distance runners [19]. Poor nutritional status acts as a deleterious co-factor on the immune system response to exercise. In fact, there is an association between insufficiency of protein and micronutrients in diet and immune dysfunction [1]. Studies focusing on the effect of single or multi-micronutrient supplementation in serum immunoglobulin response to physical training are very scarce.

Firefighters are exposed to several environmental stressors such as smoke, chemical exposure, heat, and intense physical exertion $[20,21]$. Thus, it is reasonable to seek nutritional resources, trying to mitigate the metabolic effects of the imposed training load. Typically, firefighter recruits are selected from an initial population of around several candidates and selected through demanding physical tests and careful medical checks. After these procedures, the top recruits join the recruiting process. During the recruit training period, firefighter recruits are exposed to greater physical stress than professional firefighters in their regular training. This is because during the training process of recruits, stressful situations are experienced systematically and with greater incidence. Thus, we analysed the influence of multi-micronutrient supplementation on resting serum immunoglobulins in subjects undergoing an intensive physical training program. It was hypothesised that increasing micronutrient intake would enhance the immunoglobulin response to five weeks of strenuous training.

\section{Materials and Methods}

The participants in this study were chosen from an initial population of around 200 candidates who were selected through physical fitness tests. The top 25 joined the recruiting process. Subjects with any incapacitating physical or organic pathology were excluded. One firefighter recruit was excluded due to a shoulder injury prior to the experiment.

\section{Sample}

Twenty-four male firefighters were randomly divided into supplemented and placebo groups (concealed allocation was implemented). Regarding inclusion criteria, subjects should be professional firefighter recruits, healthy (assessed through medical tests), with no muscular bone or articular pathologies, without visual or hearing deficits, and be classified in physical conditioning tests. Age, anthropometrics, and physical conditioning characteristics were similar between groups ( $\triangleright$ Table 1 ), with no dropouts during the study. All participants were informed about the benefits and risks of participating in the current study prior to signing an informed consent form, which was approved by the ethics board of the local university. Experimental procedures were in accordance with the Helsinki Declaration and ethical principles for medical research involving human subjects [22]. 


\section{Testing protocol}

The present study was randomized, double-blinded, and placebocontrolled with the supplemented group receiving, over 35 consecutive days, a proprietary supplement (Prisfar Ever-Fit Plus with

- Table 1 Means and standard deviation ( $\pm S D$ ) values of age, anthropometrics, and physical conditioning characteristics of supplemented and placebo group.

\begin{tabular}{|l|c|c|l|}
\hline Variables & $\begin{array}{l}\text { Supplemented } \\
(\mathbf{n = 1 2})\end{array}$ & $\begin{array}{l}\text { Placebo } \\
(\mathbf{n = 1 2})\end{array}$ & $\begin{array}{l}\text { Paired } \\
\text { t-test }\end{array}$ \\
\hline Age (years) & $22.1 \pm 1.9$ & $23.9 \pm 0.3$ & $\mathrm{~ns}$ \\
\hline Height $(\mathrm{cm})$ & $174.5 \pm 3.8$ & $174.3 \pm 3.5$ & $\mathrm{~ns}$ \\
\hline Body mass $(\mathrm{kg})$ & $68.9 \pm 7.4$ & $69.3 \pm 12.3$ & $\mathrm{~ns}$ \\
\hline Fat mass (\% body mass) & $9.6 \pm 2.0$ & $10.2 \pm 2.0$ & $\mathrm{~ns}$ \\
\hline $\begin{array}{l}\text { Bench press with 50 kg } \\
\text { (reps) }\end{array}$ & $12.0 \pm 7.1$ & $13.7 \pm 5.7$ & $\mathrm{~ns}$ \\
\hline Chin-ups (reps) & $15.8 \pm 0.7$ & $15.7 \pm 2.1$ & $\mathrm{~ns}$ \\
\hline Sprint 50 m (s) & $7.00 \pm 0.0$ & $6.97 \pm 0.05$ & $\mathrm{~ns}$ \\
\hline Cooper test (m) & $3007 \pm 127$ & $3120 \pm 106$ & $\mathrm{~ns}$ \\
\hline $\begin{array}{l}\text { Relative peak power } \\
\text { output (watt/kg) }\end{array}$ & $10.5 \pm 0.5$ & $10.8 \pm 0.1$ & $\mathrm{~ns}$ \\
\hline $\begin{array}{l}\text { Relative mean power } \\
\text { output (watt/kg) }\end{array}$ & $7.8 \pm 0.5$ & $8.1 \pm 0.3$ & $\mathrm{~ns}$ \\
\hline $\begin{array}{l}\text { Relative minimum power } \\
\text { output (watt/kg) }\end{array}$ & $5.7 \pm 0.8$ & $5.8 \pm 0.6$ & $\mathrm{~ns}$ \\
\hline Fatigue index (\%) & & $45.2 \pm 6.8$ & $\mathrm{~ns}$ \\
\hline Squat jump (cm) & $45.9 \pm 6.4$ & $37.8 \pm 3.5$ & $\mathrm{~ns}$ \\
\hline $\begin{array}{l}\text { Countermovement jump } \\
\text { (cm) }\end{array}$ & $37.3 \pm 5.7$ & $39.4 \pm 5.8$ & $\mathrm{~ns}$ \\
\hline ns: t-test non-significant $(\mathrm{p}>0.05) ;{ }^{*}$ Wingate test. & \\
\hline \multicolumn{2}{|l|}{} & \\
\hline
\end{tabular}

$15 \mathrm{mg}$ of beta carotene, $200 \mathrm{mg}$ of vitamin C, $136 \mathrm{mg}$ of vitamin E, $200 \mu \mathrm{g}$ of selenium, $15 \mathrm{mg}$ of zinc and $100 \mathrm{mg}$ of magnesium). The other group received a placebo powder (maltodextrin with artificial flavour and colour). The training period included 5 microcycles of 5 training units (including 30 min of military drills plus 90 min of technical skills with and without fire protective clothing) and 2 resting days. This and the contents of the weekly physical training program are displayed in $>$ Fig. 1. Participants avoided physical exertion over the weekends during the study period. Anthropometrical evaluation included stature; body mass; tricipital, bicipital, subscapular, and suprailiac skinfold thickness; and fat mass [23].

All participants received the same physical training and professional skills program during 3 months prior to the experiment. Physical fitness in-between groups was similar at the beginning of the study ( $>$ Table 2 ). Dietary intake was assessed on 2 weekdays and one weekend day record (one week before the intervention) by means of a photo album with 134 pictures containing average raw/cooked food portions. Mean daily food intake was converted to nutrients using ESHA's Food Processor Nutrition Analysis software [24]. Dietary intake values prior to the experiment were similar between groups ( $\triangleright$ Table 2 ). Because the groups presented similar nutritional intake before intervention and firefighters had the same meals during the intervention, they were not tested again for these variables.

For serum immunoglobulin concentrations assessments, venous blood samples were drawn from an antecubital vein in a fasting state always at 8:00 a.m., on the first Monday after the resting days, at pre- ( 3 months after the start of training activities) and post- 5 weeks of supplementation. The serum immunoglobulin concentrations were determined using specific $\mathrm{N}$ antiserum to human $\mathrm{gG}$, $\lg A$, and $\lg \mathrm{M}$ (code numbers OSAS, OSAR, and OSAT, respectively).

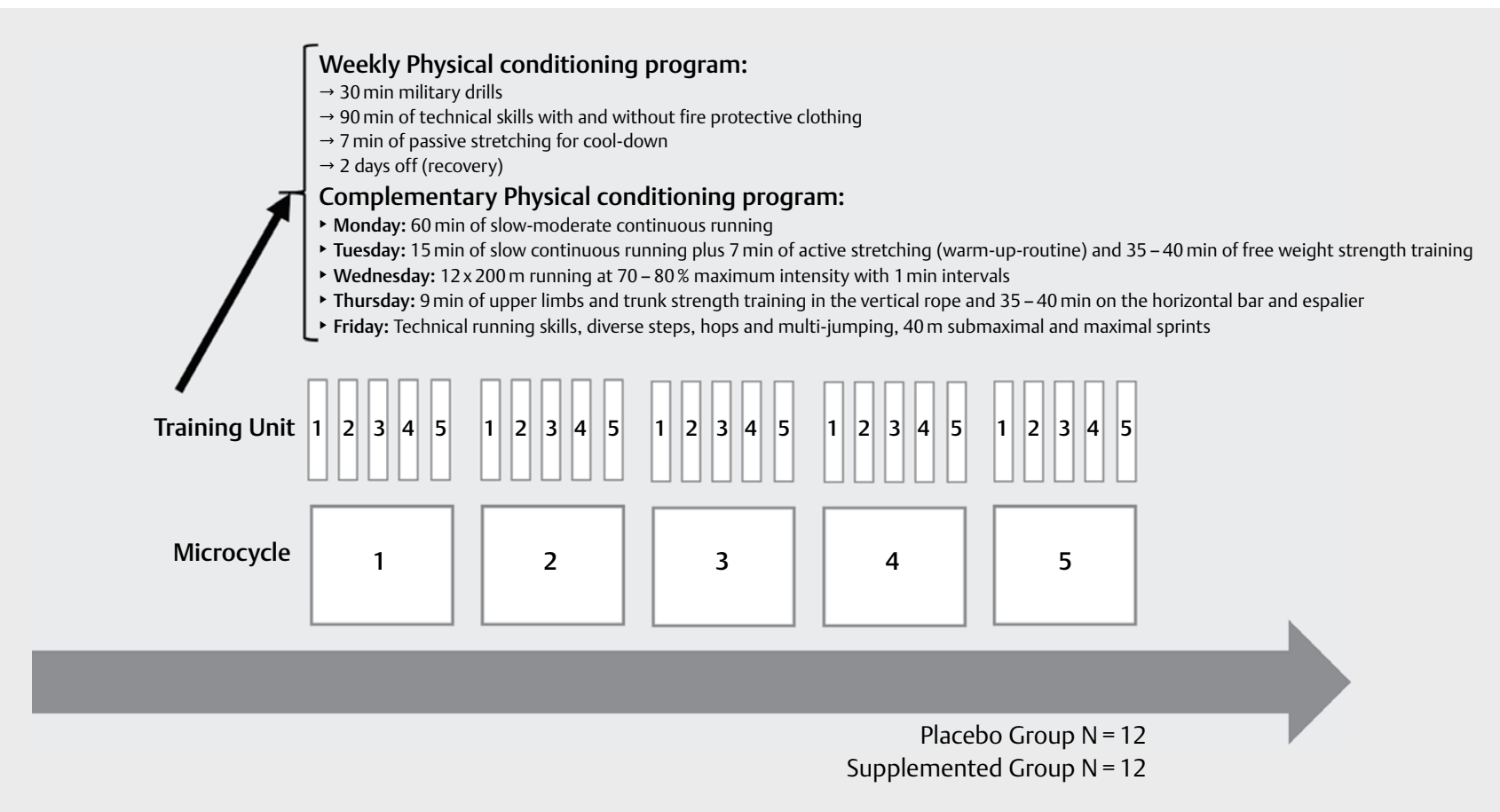

- Fig. 1 The physical training program. 
The immune complexes formed were measured in a Behring nephelometer (Dade Behring Marburg GmbH, Newark, NJ, USA) and the amount of $\mathrm{ggG}, \lg A$, and $\mathrm{IgM}$ were calculated by comparison with standards of known concentration. Blood samples were analysed in the same laboratory following common analytical procedures.

\section{Statistical analysis}

A sample size of 24 subjects was deemed adequate ( $G$ * Power 3.1.9.2 software; Heinrich Heine Universität Düsseldorf, Germany), assuming 0.65 of effect size, $85 \%$ of statistical power, and 0.05 $\alpha$ error probability. Data were first tested for distribution normality and variance homogeneity. The effects of supplementation (experimental vs. placebo), time (pre-vs. post-supplementation), and interaction (supplementation $\times$ time) were assessed for each variable using a mixed ANOVA. A paired measures t-test (post hoc) was used to compare $\lg G$, IgA, and $\lg M$ values, before and after the fiveweek period, between both supplemented and placebo groups (between- and within-group). IBM SPSS Statistics for Windows, Version 19.0 (IBM Corp., Armonk, NY, USA) was used with results presented as mean plus standard deviation (alpha significance level was established at 0.05).

\section{Results}

Mean and standard deviation ( \pm SD) values of $\mathrm{gg}$, IgA, and $\lg M$ for supplemented and placebo groups before and after the training period are displayed at $\downarrow$ Table 3 . Interaction (supplementa-

- Table 2 Means and standard deviation ( \pm SD) values regarding nutritional intake before supplementation for both groups.

\begin{tabular}{|l|c|c|l|}
\hline & $\begin{array}{l}\text { Supplemented } \\
(\mathbf{n = 1 2})\end{array}$ & $\begin{array}{l}\text { Placebo } \\
(\mathbf{n = 1 2})\end{array}$ & $\begin{array}{l}\text { Paired } \\
\text { t-test }\end{array}$ \\
\hline Energy intake $(\mathrm{kcal})$ & $3050 \pm 600$ & $2985 \pm 580$ & $\mathrm{~ns}$ \\
\hline Carbohydrate $(\%)$ & $51.2 \pm 5.8$ & $50.8 \pm 3.1$ & $\mathrm{~ns}$ \\
\hline Protein $(\%)$ & $18.4 \pm 2.5$ & $19.2 \pm 2.1$ & $\mathrm{~ns}$ \\
\hline Fat $(\%)$ & $30.2 \pm 3.3$ & $30.8 \pm 2.8$ & $\mathrm{~ns}$ \\
\hline Vitamin C $(\mathrm{mg})$ & $147.2 \pm 58.2$ & $152.8 \pm 47.3$ & $\mathrm{~ns}$ \\
\hline Vitamin E $(\mathrm{mg})$ & $7.9 \pm 2.3$ & $8.3 \pm 2.8$ & $\mathrm{~ns}$ \\
\hline Beta carotene $(\mu \mathrm{g})$ & $165.1 \pm 4.3$ & $158.3 \pm 7.2$ & $\mathrm{~ns}$ \\
\hline Magnesium $(\mathrm{mg})$ & $431.4 \pm 76.8$ & $411.9 \pm 82.5$ & $\mathrm{~ns}$ \\
\hline Selenium $(\mu \mathrm{g})$ & $163.3 \pm 22.7$ & $161.9 \pm 54.2$ & $\mathrm{~ns}$ \\
\hline Zinc $(\mathrm{mg})$ & $16.9 \pm 5.7$ & $17.1 \pm 4.2$ & $\mathrm{~ns}$ \\
\hline \multicolumn{4}{|l}{} \\
\hline
\end{tabular}

tion $\times$ time) was not significant for any variable ( $\mathrm{gG} \eta^{2}: 0.006$, $p=0.60$, power: $0.08 ; \operatorname{lgA} \eta^{2}: 0.003 ; p=0.70$; power: 0.06 ; $\operatorname{lgM} \eta^{2}$ : $0.003 ; p=0.70$; power: 0.06$)$. Supplementation effect was detected for lgG (eta-squared, $\eta^{2}: 0.09 ; p=0.035$; power: 0.56$), \operatorname{lgA}\left(\eta^{2}\right.$ : $0.24 ; p=0.001$; power: 0.95$)$, and $\operatorname{lgM}\left(\eta^{2}: 0.09 ; p=0.036\right.$; power: $0.56)$. Time effect was not significant for any immunoglobulin (lgG $\eta^{2}: 0.003, p=0.73$, power: $0.06 ; \lg A \eta^{2}: 0.003 ; p=0.71$; power: 0.06 ; IgM $\eta^{2}: 0.015 ; p=0.42$; power: 0.12 ). Although IgA was different between groups at baseline (mean difference: $42.58 ; 95 \% \mathrm{Cl}$ : 7.00 to $78.16 \mathrm{mg} / \mathrm{dL} ; p=0.021 ; d=2.48$ ), within-group analyses (before vs. after five weeks) showed no differences. The IgG and IgM were similar at baseline, but IgG decreased (mean diff.: 46.4; $95 \% \mathrm{Cl}: 6.7$ to $86.1 \mathrm{mg} / \mathrm{dL} ; p=0.03 ; d=0.74)$ and $\mathrm{lgM}$ increased in the control group (mean diff.: $-10.7 ; 95 \% \mathrm{Cl}$ : -15.8 to $-5.5 \mathrm{mg} /$ $\mathrm{dL} ; p=0.001 ; d=-1.33)$.

\section{Discussion}

The main aim of this study was to verify the influence of multi-micronutrient supplementation on resting serum immunoglobulins in subjects undergoing an intensive physical training program. Our results suggest that despite mean values having remained within the reference values, changes observed for immunoglobulin $\mathrm{G}$ and $M$ may reflect some immune protection for firefighters engaged in recruit training. Different endogenous and exogenous stressors (e. g. light, temperature, metabolism) constantly challenge human body homeostasis and induce adaptive immune changes [8]. Immunoglobulins are protective proteins produced by the immune system in response to foreign substances called antigens. Antigens are viruses and bacteria as well as deleterious substances produced by the body itself [2]. The reduction of plasma and mucosal levels of immunoglobulins open the window for the emergence of various opportunistic infections while abnormal increases in immunoglobulins levels can trigger allergic situations [2]. Physical exercise is one of the stressors which the human body needs to handle. Thus, people engaged in regular exercise make use of many types of workouts and different combinations of exercise modes in their training sessions. Each one presents unique characteristics and challenges regarding its duration, intensity, rest interval, environmental conditions, and personal abilities [7].

It is described that intensive exercise triggers the release of large amounts of autoantigen [5], which can promote serum immunoglobulin increase [25] or decrease [26], depending on exercise type. While 2 hours of intensive judo induced an increase in serum IgG

- Table $3 \mathrm{lgG}$, IgA, and IgM for the supplemented (SUP) and placebo (PLA) groups before and after the training period.

\begin{tabular}{|c|c|c|c|c|c|c|}
\hline Variables & Group & Before & Mean diff (95\%Cl); Sig.; Cohen's d & After & \multicolumn{2}{|l|}{ Mean diff (95\%Cl); Sig.; Cohen's d } \\
\hline & & & Between-Group (Before) & & \multicolumn{2}{|l|}{ Within-Group (Before vs. After) } \\
\hline $\operatorname{lgG}(\mathrm{mg} / \mathrm{dL})$ & SUP & $909.0 \pm 120.7$ & 90.50 (-63.9 to 244.9$) ; 0.237 ; 1.21$ & $918.9 \pm 171.2$ & $-9.9(-61.8$ to 42.0$) ; 0.68 ;-0.12$ & $\approx$ \\
\hline & PLA & $818.5 \pm 228.0$ & & $772.1 \pm 216.1$ & 46.4 (6.7 to 86.1$) ; 0.03^{*} ; 0.74^{*}$ & $\downarrow$ \\
\hline $\operatorname{lgA}(\mathrm{mg} / \mathrm{dL})$ & SUP & $176.5 \pm 42.2$ & 42.58 (7.00 to 78.16$) ; 0.021^{*} ; 2.48^{*}$ & $186.1 \pm 48.5$ & $-9.6(-24.5$ to 5.4$) ; 0.19 ;-0.40$ & $\approx$ \\
\hline & PLA & $133.9 \pm 41.8$ & & $133.7 \pm 43.3$ & 0.2 (-8.8 to 9.3$) ; 0.95 ; 0.01$ & $\approx$ \\
\hline $\operatorname{lgM}(\mathrm{mg} / \mathrm{dL})$ & SUP & $65.9 \pm 20.2$ & $-16.00(-41.2$ to 9.25$) ; 0.202 ; 0.01$ & $69.7 \pm 20.8$ & $-3.8(-7.8$ to 0.1$) ; 0.06 ;-0.61$ & $\approx$ \\
\hline & PLA & $81.9 \pm 37.0$ & & $92.6 \pm 40.5$ & $-10.7(-15.8$ to -5.5$) ; 0.001^{*} ;-1.33^{*}$ & $\uparrow$ \\
\hline
\end{tabular}


concentration, low- to moderate-intensity exercise did not promote significant changes in IgG levels [26]. To study the effects of training and acute exercise on immunoglobulin levels, Nieman et al. [27] matched eleven marathon runners with nine sedentary controls in three moments: baseline, after a graded maximal treadmill test, and $45 \mathrm{~min}$ of recovery. The results showed that at no point in the study did the groups differ. Conversely, $45-75 \mathrm{~km}$ of running depressed serum immunoglobulin levels for up to two days [8]. It seems that the longer the exercise, the greater the acute decrease in the concentration of immunoglobulins and the longer the time to return to baseline values.

For standard workouts, $24 \mathrm{~h}$ are usually sufficient to recover basal levels of serum immunoglobulin after a single bout of severe exercise [23]. Acute exercise-induced changes in serum immunoglobulin levels do not appear to be translated into chronic adaptation [23]. It was observed that a training program that consisted of $3 \mathrm{~km}$ jogging, three times per week for eight weeks did not alter basal IgG, IgA, and IgM serum concentrations in untrained male subjects, perhaps due to its low intensity. It seems that acute changes in serum immunoglobulin concentrations are reversible as quickly as exercise intensity lessens. Although several studies $[8,27]$ suggest the reversibility of acute adaptations induced by exercise in serum concentrations of immunoglobulins, it is debatable whether some chronic adaptations occur.

Baseline values from our study showed differences between groups only for IgA. Nonetheless, trivial differences observed IgG and IgM must be considered circumstantial because the values all fall within the normal range. Stability was observed in the supplemented group for all immunoglobulin values. In the control group, immunoglobulin patterns were irregular, i. e. IgG decreased and IgM increased whereas IgA remain stable. The administration of the maltodextrin might have contributed to acute changes during the training process [7], but our results point to the lack of chronic effects on serum IgA concentrations because post-values were similar to pre-values.

Although the supplemented group showed stable values for these markers, the subjects' responses were inconsistent. That said, it is important to highlight that the kinetics of leukocyte subset changes and their by-products cannot be fully appreciated in studies where pre-and post-exercise blood sample are compared, i.e. it is not possible to follow the time-dependent changes. However, as the participants' inclusion in each group was randomized, it can be speculated that the observed responses are circumstantial and define a special immunological trait at the time of the study or possibly the influence of smoking habits (because two subjects in supplemented group and seven subjects in placebo group were regular smokers). It seems that smoking reduces secretory IgA [28]. It was suggested that the raised IgM during the first $12 \mathrm{~h}$ after exercise reflects a secondary antibody response to autoantigens [2]. $\operatorname{lgA}$ in serum tends to be stable even after high-intensity training [11], which justifies the stability of our results independent of the difference between groups. Regardless of the differences observed in the placebo group, we should not assume that these differences have any physiological significance, because the variations are within the literature reference values for serum immunoglobulins.

All variable values for both groups were within the normal laboratory range $[29,30]$. They were similar to those found before and after a period of long intensive training [31] but lower than those observed in orienteers and runners/skiers [32]. Perhaps the severity of firefighter training, by inducing severe physical and psychological stress, depressed some immunoglobulin serum concentrations, in line with previous results [33]. However, supplementation seems to have stabilized the immune response to training in the present study because the placebo group expressed alterations for IgG and IgM.

It seems that training status does not promote significant changes in serum immunoglobulin concentrations. A comparison of marathoners and sedentary subjects verified that $\lg G, \operatorname{lgA}$, and IgM serum levels did not differ during rest, graded maximal exercise, and recovery [27]. It was also observed that different exercise types (varying in intensity and duration) did not alter basal IgG, IgA, and IgM serum concentrations [1], similar to what happens before vs. after a volleyball season [25]. It was previously stated that IgG and IgM are maintained at a higher level in exercised subjects [9]. However, the early immunoglobulin increase subsequent to the initial exercise loads is attenuated by hard training continuity [12]. The results from the present study partially conflict with this assumption because the placebo group suffered a serum IgG reduction at the time of the second evaluation. Although low- to moderate-intensity training tends to stimulate the production of $\mathrm{gGC}$ [1] and $\lg A[1,12]$, continued high-intensity exertion promotes a significant decrease of $\mathrm{IgG}$ and $\operatorname{lgM}$ without an alteration in $\lg \mathrm{A}$ serum concentration [11]. Thus, the current results for IgA are supported by other studies. The IgG decrease in the placebo group is in accordance with Mashiko et al. [11]. However, the IgM increase verified in the placebo group is partially supported by the literature, which verified that a reduction in IgM serum concentration after a period of hard training was followed by an increase before competition probably due to the recovery process in the tapering phase [31]. The IgM increase verified in our placebo group cannot be attributed to tapering because the training program volume and intensity was maintained without any recovery phases. It can be speculated that if two days of rest are sufficient to return the values to their basal expression, changes in the control group and stability in the supplemented group point to a certain stabilizing effect of the chosen supplementation.

The exercise immune response modulation with nutritional supplementation suggests some positive effect of micronutrient supplementation in inhibiting eventual exacerbation of autoimmune inflammatory responses to intensive training continuity [34]. This finding partially corroborates that of Vidal et al. [14], who verified that a milk-based wolfberry formulation increased serum IgG levels in healthy sedentary elderly. It was also verified that bovine colostrum protein concentrate prevented a drop in post-exercise serum IgG concentration in highly trained cyclists [18]. However, bovine colostrum supplementation did not alter serum IgG and salivary IgA concentrations during periods of strength and speed training [35].

In healthy non-active well-fed subjects, any type of supplementation seems to be ineffective for improving humoral immune status. For instance, humoral immune response is not enhanced by vitamin E supplementation in healthy sedentary women [36] and a salmon-rich diet (improving $n-3$ fatty acid intake) did not change serum IgG, IgM, and IgA concentrations in healthy subjects [37]. 
However, conflicting results in relation to the positive effects of vitamin E supplementation on the immune system have been observed. Even though there is no clear indication that vitamin E supplementation is necessary to improve the humoral immune functions, vitamin E supplementation may be beneficial to all adult age groups as a preventive measure for complications related to oxidative damage $[36,38]$.

Moreover, in the absence of nutritional deficiency (even in highly stressed athletes), nutritional supplementation seems be ineffective. For example, Stroescu et al. [39] observed that basal serum immunoglobulins in elite female gymnasts undergoing strenuous training did not change after supplementation with SUPRO brand isolated soy protein. However, supplementation can be effective in situations of plasma micronutrient deficiency. In asthma patients (characterized by lower levels of selenium, zinc, betacarotene, and vitamins $($ and $E$ ), a multiple-nutrient supplement recovered normal micronutrient plasma levels and improved immunoglobulin status [40]. In animal studies, selenium and vitamin E deficiency induced a decrease in $\mathrm{lg} G$ and $\operatorname{lgM}$ serum concentrations and $\lg A$ remained unchanged [41]. In addition, it was observed that supplementation can improve the immune status of healthy active subjects undergoing hard physical training when humoral immunity is depressed. In fact, it was shown that the administration of ectisten-containing tincture of leuzea and leveton restored the decrease of serum $\mathrm{gg}$ and $\mathrm{lgA}$ induced by intensive running training [42]. Studies analysing the modulation of serum immunoglobulin concentration by multi-micronutrient supplementation are lacking because single-micronutrient supplementation failed to improve immune response to exercise in well-trained and well-fed subjects.

Although differences between groups were observed only for $\operatorname{lgA}$, it can be stated that the stability of the supplemented group clearly contrasts with the changes in the placebo group. It was observed that selenium supplementation can selectively enhance human antibody production with increased switching from IgM to $\mathrm{lgG}$ production [43]. Therefore, perhaps the absence of supplementation in the placebo group could accentuate the switch from $\mathrm{lg} G$ to $\mathrm{lgM}$ production, justifying the current study results. We hypothesise that supplementation stabilized humoral immunity during hard training and that the IgM increase in the placebo group was an index of immune fragility. It is known that natural IgM antibodies induce apoptosis of transformed cells and act to rapidly remove foreign cells and particles with attenuation of the inflammatory processes [44]. The lack of studies relating to micronutrient supplementation and serum immunoglobulin status during continued, hard physical exertion does not allow deeper comparisons with current data.

However, this study points to the association between nutrition and immune changes induced by heavy physical exertion. This is an open field for scientific research. Firefighter training is aggressive in many ways, either due to the exercise intensity or due to the conditions in which it is developed. Thus, the control of immune variables is important to follow the acute effects and chronic adaptations induced by different types of exercises. However, it is important to acknowledge several shortcomings and potential limitations of our study. Although participants reported that they avoided physical exertion over the weekends during the study pe- riod, this was not monitored. Also, the kinetics of leukocyte subset changes and their by-products cannot be entirely observed when pre- and post-exercise blood samples are compared.

The results from the present study suggest that in well-fed firefighters, multi-micronutrient supplementation reduces the variations induced by a five-week strenuous physical training program in some serum immunoglobulins: IgG and IgM. Although there were significant differences in some immunoglobulins, which allows us to assume some protective effect from supplementation (as the values clearly remained within the reference values), the results obtained may have derived from normal fluctuations and not from the chronic effect of the chosen supplementation.

\section{Conflict of interest}

The authors declare that they have no conflict of interest.

\section{References}

[1] Buyukyazi G, Kutukculer N, Kutlu N et al. Differences in the cellular and humoral immune system between middle-aged men with different intensity and duration of physically training. J Sports Med Phys Fitness 2004; 44: 207-214

[2] McKune AJ, Smith LL, Semple S] et al. Immunoglobulin responses to a repeated bout of downhill running. Br J Sports Med 2006; 40: 844 . doi:10.1136/bjsm.2006.027839

[3] Janeway CTravers et al. Innate immunity: Induced innate responses to infection. In: Immunobiology: The Immune System in Health and Disease. 6th ed. New York: Garland Science; 2005: 75-95

[4] Schroeder HW Jr., Cavacini L. Structure and function of immunoglobulins. J Allergy Clin Immunol 2010; 125: S41-S52. doi:10.1016/j. jaci.2009.09.046

[5] Langereis JD, van der Flier M, de Jonge MI. Limited innovations after more than 65 years of immunoglobulin replacement therapy: potential of IgA- and IgM-enriched formulations to prevent bacterial respiratory tract infections. Front Immunol 2018; 9. doi:10.3389/ fimmu.2018.01925

[6] Klimpel GR. Immune defenses. In: Baron S, Ed. Medical Microbiology. 4th ed. Galveston: University of Texas Medical Branch at Galveston; 1996

[7] Caris AV, Da Silva ET, Dos Santos SA et al. Effects of carbohydrate and glutamine supplementation on oral mucosa immunity after strenuous exercise at high altitude: A double-blind randomized trial. Nutrients 2017; 9: 692. doi:10.3390/nu9070692

[8] Nieman DC, Nehlsen-Cannarella SL. The effects of acute and chronic exercise of immunoglobulins. Sports Med 1991; 11: 183-201. doi:10.2165/00007256-199111030-00003

[9] Martins RA, Cunha MR, Neves AP et al. Effects of aerobic conditioning on salivary IgA and plasma IgA, $\mathrm{lgG}$ and $\mathrm{IgM}$ in older men and women. Int J Sports Med 2009; 30: 906-912. doi:10.1055/s-0029-1237389

[10] Lim YM, Hong GR. Effect of 16-week Kouk-Sun-Do exercise on physical fitness, emotional state, and immunoglobulin A in community-dwelling elders in Korea. Appl Nurs Res 2010; 23: 91-100. doi:10.1016/j. apnr.2008.05.004

[11] Mashiko T, Umeda T, Nakaji S et al. Effects of exercise on the physical condition of college rugby players during summer training camp. $\mathrm{Br}$ J Sports Med 2004; 38: 186. doi:10.1136/bjsm.2002.004333 
[12] Verde TJ, Thomas SG, Moore RW et al. Immune responses and increased training of the elite athlete. J Appl Physiol (1985) 1992; 73 : 1494-1499. doi:10.1152/jappl.1992.73.4.1494

[13] Liu Y, Jing $\mathrm{H}$, Wang J et al. Micronutrients decrease incidence of common infections in type 2 diabetic outpatients. Asia Pac J Clin Nutr 2011; 20: 375-382

[14] Vidal K, Bucheli P, Gao Q et al. Immunomodulatory effects of dietary supplementation with a milk-based wolfberry formulation in healthy elderly: A randomized, double-blind, placebo-controlled trial. Rejuvenation Res 2012; 15: 89-97. doi:10.1089/rej.2011.1241

[15] Henson D, Nieman D, Davis JM et al. Post-160-km race illness rates and decreases in granulocyte respiratory burst and salivary IgA output are not countered by quercetin ingestion. Int J Sports Med 2008; 29 : 856-863. doi:10.1055/s-2007-989424

[16] Maldonado MD, Manfredi M, Ribas-Serna J et al. Melatonin administrated immediately before an intense exercise reverses oxidative stress, improves immunological defenses and lipid metabolism in football players. Physiol Behav 2012; 105: 1099-1103. doi:10.1016/j. physbeh.2011.12.015

[17] Tiollier E, Chennaoui M, Gomez-Merino D et al. Effect of a probiotics supplementation on respiratory infections and immune and hormonal parameters during intense military training. Mil Med 2007; 172: 1006-1011. doi:10.7205/milmed.172.9.1006

[18] Shing CM, Peake J, Suzuki K et al. Effects of bovine colostrum supplementation on immune variables in highly trained cyclists. J Appl Physiol (1985) 2007; 102: 1113-1122. doi:10.1152/japplphysiol.00553.2006

[19] Crooks CV, Wall CR, Cross ML et al. The effect of bovine colostrum supplementation on salivary IgA in distance runners. Int J Sport Nutr Exerc Metab 2006; 16: 47-64. doi:10.1123/ijsnem.16.1.47

[20] McAllister M], Basham SA, Smith JW et al. Effects of environmental heat and antioxidant ingestion on blood markers of oxidative stress in professional firefighters performing structural fire exercises. J Occup Environ Med 2018; 60: e3595-e3601

[21] Gaughan DM, Siegel PD, Hughes MD et al. Arterial stiffness, oxidative stress, and smoke exposure in wildland firefighters. Am J Ind Med 2014; 57: 748-756. doi:10.1002/ajim.22331

[22] Harriss DJ, MacSween A, Atkinson G. Ethical standards in sport and exercise science research: 2020 update. Int J Sports Med 2019; 40: 813-817. doi: 10.1055/a-1015-3123

[23] Siri WE. Body composition from fluid spaces and density: Analysis of methods.In: Brozek J, Henschel A, Eds. Techniques for Measuring Body Composition. Washington, DC: National Academy of Sciences, National Research Council; 1961: 223-244

[24] Bazzano LA, He J, Ogden LG et al. Agreement on nutrient intake between the databases of the First National Health and Nutrition Examination Survey and the ESHA Food Processor. Am J Epidemiol 2002; 156: 78-85. doi.org/10.1093/aje/kwf003

[25] Córdova A, Sureda A, Tur JA et al. Immune response to exercise in elite sportsmen during the competitive season. J Physiol Biochem 2010; 66: 1-6. doi:10.1007/s13105-010-0001-2

[26] Aldred S, Love JA, Tonks LA et al. The effect of steady state exercise on circulating human $\mathrm{IgE}$ and $\mathrm{IgG}$ in young healthy volunteers with known allergy. J Sci Med Sport 2010; 13: 16-19. doi:10.1016/j. jsams.2008.07.001

[27] Nieman DC, Tan SA, Lee JW et al. Complement and immunoglobulin levels in athletes and sedentary controls. Int J Sports Med 1989; 10: 124-128. doi:10.1055/s-2007-1024887

[28] Avşar A, Darka O, Bodrumlu EH et al. Evaluation of the relationship between passive smoking and salivary electrolytes, protein, secretory
IgA, sialic acid and amylase in young children. Arch Oral Biol 2009; 54 : 457-463. doi:10.1016/j.archoralbio.2009.01.017

[29] Dati F, Schumann G, Thomas L et al. Consensus of a group of professional societies and diagnostic companies on guidelines for interim reference ranges for 14 proteins in serum based on the standardization against the IFCC/BCR/CAP Reference Material (CRM 470). International Federation of Clinical Chemistry. Community Bureau of Reference of the Commission of the European Communities. College of American Pathologists. Eur J Clin Chem Clin Biochem 1996; 34: 517-520

[30] Kratz A, Ferraro M, Sluss PM et al. Normal reference laboratory values. N Engl J Med 2004; 351: 1548-1563. doi:10.1056/NEJMcpc049016

[31] Hejazi K, Hosseini SR. Influence of selected exercise on serum immunoglobulin, testosterone and cortisol in semi-endurance elite runners. Asian J Sports Med 2012; 3: 185-192

[32] Lannergård A, Fohlman ], Wesslén L et al. Immune function in Swedish élite orienteers. Scand J Med Sci Sports 2001; 11: 274-279. doi:10.1034/j.1600-0838.2001.110504.x

[33] Pyne DB, Gleeson M. Effects of intensive exercise training on immunity in athletes. Int J Sports Med 1998; 19: S183-S191; discussion S191-184. doi:10.1055/s-2007-971991

[34] Moreira A, Kekkonen RA, Delgado L et al. Nutritional modulation of exercise-induced immunodepression in athletes: A systematic review and meta-analysis. Eur J Clin Nutr 2007; 61: 443-460. doi:10.1038/ sj.ejcn. 1602549

[35] Mero A, Miikkulainen H, Riski J et al. Effects of bovine colostrum supplementation on serum IGF-I, IgG, hormone, and saliva IgA during training. J Appl Physiol (1985) 1997; 83: 1144-1151. doi:10.1152/ jappl.1997.83.4.1144

[36] Park OJ, Kim HY, Kim WK et al. Effect of vitamin E supplementation on antioxidant defense systems and humoral immune responses in young, middle-aged and elderly Korean women. J Nutr Sci Vitaminol 2003; 49: 94-99. doi:10.3177/jnsv.49.94

[37] Kelley DS, Dougherty RM, Branch LB et al. Concentration of dietary n-6 polyunsaturated fatty acids and the human immune status. Clin Immunol Immunopathol 1992; 62: 240-244. doi: 10.1016/00901229(92)90078-3

[38] Ibrahim E, Alexa LM. The role of the status of selected micronutrients in shaping the immune function. Endocr Metab Immune Disord Drug Targets 2019; 19: 1100-1115. doi: 10.2174/18715303196661905291 01816

[39] Stroescu V, Dragan J, Simionescu L et al. Hormonal and metabolic response in elite female gymnasts undergoing strenuous training and supplementation with SUPRO brand isolated soy protein. J Sports Med Phys Fitness 2001; 41: 89-94

[40] Guo CH, Liu P], Lin KP et al. Nutritional supplement therapy improves oxidative stress, immune response, pulmonary function, and quality of life in allergic asthma patients: an open-label pilot study. Altern Med Rev 2012; 17: 42-56

[41] Bauersachs S, Kirchgessner M, Paulicks BR. Effects of different levels of dietary selenium and vitamin $E$ on the humoral immunity of rats. J Trace Elem Electrolytes Health Dis 1993; 7: 147-152

[42] Azizov AP, Seifulla RD, Chubarova AV. Effects of leuzea tincture and leveton on humoral immunity of athletes. Eksperimental'naia $\mathrm{i}$ Klinicheskaia Farmakologiia 1997; 60: 47-48

[43] Reinhold U, Pawelec G, Enczmann J et al. Class-specific effects of selenium on PWM-driven human antibody synthesis in vitro. Biol Trace Elem Res 1989; 20: 45-58. doi:10.1007/bf02919097

[44] Brändlein S, Vollmers HP. Natural IgM antibodies, the ignored weapons in tumour immunity. Histol Histopathol 2004; 19: 897-905. doi:10.14670/hh-19.897 